participants with fresh and stimulating information. The Institute of 'Technology at Haifa, the Negev Institute in Boorsheba, the climatic unit at the Tel Hashomer hospital in Tel Aviv, and the French centre for study and information on human problems in arid zones (PROHUZA), have all contributed significantly to our knowledge of heat physiology; and Unesco has done well to fostor, throughout its major project on scientific research on arid lands, studies which are carried out in the field rather than in climatic chamber's in temperate countries. Doveloping communities in arid regions, given a now way of life and now standards of hygiene, must sooner or later face the issues of how the local climate affects health and industrial programmes; and the studies which have been made so far, principally on expatriate European and Amorican ('ommunities, are not altogether relevant. In this respect the work of W. V. Macfarlane (Australia) on long-term heat adaptations in domestic stock animals is particularly valuable, and it is encouraging to learn that similar comparative research is carried out in Egypt and at the Central Indian Arid Zone Research Institute in Jodhpur. and that the PROHUZA team has examined the indus. trial-omployment aptitude and long-term adaptations of nomadic tribes in the Sahara.

The visiting participants at the Ineknow symposium are indebted to Unesco and the Govermment of India, and to Dr. B. Mukerji for his hospitality at the Central Drug Research Institute. The published Proceedings will contain much valuable information anel should stimulate continued interest in the subjoct in the Middle East and in South-East Asia.

C. S. LETTHEA1)

\title{
CARDIOVASCULAR ANATOMY AND PATHOLOGY
}

\section{A}

SYMPOSIUM on 'Cardiovascular Anatomy and Prof. K. R. Hill, was held in the meeting room of the Zoological Society of London during November 28-29, 1962. This symposium, which was attended by more than 100 research workers from a wide variety of medical and veterinary departments, reflected the growing interest in the functional anatomy and pathology of the cardiovascular system.

During the first morning session, under the chairmanship of Prof. E. W. Walls, Prof. F. Navarrina Gamez (Santiago de Compostela, Spain) described researches conducted in collaboration with Prof. R. G. Harrison on the effect of cortisone on the vascularization of bone in normal and ovariectomized female rats. These researches, like others during the symposium, demonstrated the need for a detailed analysis of the functional anatomy of organs and tissues when investigating their vascularization. During the first four weeks after ovariectomy there is a reduction in the extent of vascularization of the metaphyses and vertebral bodies. This is not as extensive as in cortisonetreated rats, however, and is followed, within ten weeks, by an increased vascularization. The primary metaphyseal ischæmia can be correlated with a disorganization of cell columns in the epiphyseal cartilages of long bones, which persisted in cortisone-treated rats. These alterations in vascular pattern are accompanied by changes in the pattern and density of trabeculæ in metaphyses and vertebræ; in some animals there is an obvious fragmentation of trabeculæ in vertebral spines.

Dr. Helen N. Duke (London) summarized her investigations on the hæmodynamics of the pulmonary circulation. Factors concerned with the pressure and flow and change of blood volume in the circulation were discussed. The pressure flow is concave to the flow axis. The curve is affected by changes of left atrial pressure and by vasomotor reactions of the pulmonary blood vessels. Increase of pulmonary arterial inflow rate or left atrial pressure increases the volume of blood in the pulmonary blood vessels; some of the increased blood volume is the result of capillary dilatation. It is probable that those vessels responsible for pulmonary vascular resistance are not those responsible for changes in lung blood volume.

The functional anatomy of the vertebral venous system was described by Dr. J. D. W. Tomlinson (London). The variability of the posterior vena cava, particularly among aquatic mammals, was clearly and beautifully demonstrated. The value of the azygos venous system as a collateral circulation for drainage of structures below the level of the diaphragm was also discussed.

Dr. R. L. Holmes (Birmingham) reviewed present-day knowledge on the anatomy of the hypothalamo-hypophyseal vascular system, with particular relation to the hedgehog and ferret, and showed that there is no isolation of the vascular supply of one part of the gland from that of another or from the hypothalamus. The portal vessels are responsible for carrying the greater part of the normal blood supply to the pars distalis, and play a major part in the mediation of hypothalamic control over the pituitary.

In the afternoon session on November 28, under the chairmanship of Prof. Harrison, Mr. D. Sykes (Liverpool) reviewed some of his work on the blood supply of the human kidney. There is a segmental pattern of branching of the renal artery within the substance of the kidney which is, however, subject to some variation. A continuous arcuate artery does not exist. The venous pattern does not correspond with the arterial supply, and evidence was presented to suggest that blood vessels which penetrate the kidney capsule are carrying blood which is passing centripetally into the substance of the kidney. The longitudinal sulcus, when it exists, does not correspond with Brodel's line, which is neither linear nor avascular.

Mr. D. B. Moffat (Cardiff) summarized the research work which he had been conducting with Dr. Julia Fourman on the fine vascularization of the mammalian kidney; he: demonstrated the difference to be found in various mammalian species, and clarified the nature of the vasa recta, which he found to be mostly composed of capillaries.

Prof. D. F. M. Bunce II (Des Moines, Iowa) read a paper on the architecture of the distended arterial wall, and stressed the differences in histological appearance of arteries in the collapsed and distended state, and between arteries from various sites in the body. In the teaching of students he had found the use of casts of the renal vascular tree of great value for their appreciation of the true nature of glomerular structure.

Dr. J. L. Braithwaite (Liverpool) described experiments he had been conducting with Dr. C. J. Fairhurst on collateral venous drainage of the spleen. Pursuing his original investigations on the regional distribution of the splenic vessels and their branches to the rat spleen, he had shown that the venous drainage of a region of the spleen the hilar vein of which had been occluded was effected through a plexus of newly formed veins encircling the site of ligature. Following interruption of the main splenic vein, collateral channels, consisting of preformed anastomoses (evident at $24 \mathrm{~h}$ ) newly formed vessels (visible at 7 days) and portal-systemic anastomoses (which developed 3 weeks later), became established.

Dr. J. E. Wright (Liverpool) concluded the afternoon session by deseribing the effects of interruption of the vascular pedicles of the liver in the experimental animal, and compared the effects of ligation of the hepatic artery with those of interruption of the portal vein. Arterial 
ligation was not followed by either atrophy or necrosis, and was accompanied by the enlargement of œsophageal and omental anastomoses, and a peribiliary plexus of vessels coursing along the wall of the bile duct. Interrup. tion of the portal vein was fatal within a few hours of operation in all cases in which the main trunk was ligated; ligation of the central lobar branch of the portal vein resulted in atrophy of the central lobe of the liver, and compensatory hypertrophy of the quadrate lobe.

During the morning session on November 29, under the chairmanship of Prof. W. I. Beveridge, Dr. R. Finlayson (London) gave a short account of the pathology and the incidence of arterial disease as it occurs in wild animals in captivity. Vascular lesions were described in fish, amphibia, reptiles, birds and mammals. Atherosclerosis is seen commonly only in some avian orders and occlusive atherothrombosis is extremely rare in animals. Age is the only factor shown to be fairly directly related to atherosclerosis, but the virtual absence of this condition in some comparatively old animals emphasizes that atheroma is not an inevitable accompaniment of senescence. The role of dietary and other factors which may play a part in the pathogenesis was discussed briefly.

Dr. B. McKinney, of Makerere College, Uganda, East Africa, gave an account of his investigations into arterial lesions discovered in free-living wild animals in East Africa. These were particularly prevalent among ruminants such as buffalo and antelopes, a surprising result in animals which fod only on herbage and the fat intake of which would be largely composed of unsaturated fatty acids. It had been suggested that ruminal digestion resulted in a high intake of acetic and butyric acids which might account for this, but the author discounted the suggestion that this factor could be of significance.

Dr. H. M. Pirie (Glasgow) gave an account of cardiovascular disease in domestic animals as seen in routine studies post mortem. He described a wide range of lesions from the ancurysms commonly found in horses associated with vascular invasion by nematode larvæ (Strongylus vulgaris) to atheroma of pigs and the atheroma-like lesions often seen in the coronary arteries of dogs.

On the experimental and physiological side, Dr. J. Poole (Oxford) described his work on experimental studies on growth of aortic tissue in baboons. He has used tissueculture methods from which he believed that aortic endothelium was related to smooth muscle. Dr. A. F. Munro and Dr. R. S. F. Campbell (Glasgow) gavo an account of their work on the respiratory metabolism of blood vessels from difforent spocies. The authors had ovolved the technique of measurement of oxygen consumption by normal and discased aortæe and had found significant impairmont in the latter.

During the afternoon session, under the chairmanship of Prof. K. R. Hill. Dr. M. Craw ford (London) described the epidemiology of coronary artery disease. Coronary artery disease cannot be regarded as a disease entity but is made up of two components; (1) mural atheroma ; (2) occlusion of the lumen; which are obviously related, but are different from each other. Epidemiological evidence shows that occlusion of the lumen appears to be related, to physical activity and associated with certain diseases such as peptic ulcer, whereas mural atheroma appears to have no relation to these factors. In general, there appears to be an increase in prevalence of coronary occlusive disease among the populace, but not of mural atheroma.

Dr. Jack P. Strong (New Orleans) made some observa tions on the natural history and geographic pathology of human atherosclerosis. A geographical study of coronary artery disease has shown that white males are more severely involved than other sex or race groups. Aortic fatty streaks are practically universal after the first decade of life, but population differences in the formation of fibrous plaques seem to parallel suspected differences in the clinical manifestations of atherosclerotic heart discase.

Dr. M. I. Wright (London) discussed age changes in peripheral arteries of man. Peripheral arteries were examined from twelve sites at all ages. 'Two groups of change from the typical infant pattern were found : those which appeared to be associated with growth; namely. muscular elastic cushions, thickening intima, longitudinal elastin fibres, loss of continuity and swelling and beading of the internal elastic lamina, and a layer or layers somewhat resembling the internal elastica. The second group of changes includes small plaques of calcification of the internal elastica, and accumulation of excessive mucepolysaccharide in the media; these are seen best and carliest in the arteries of the leg in adult life.

Prof. s. Gero (Budapost) deseribed his work in relation to mucopolysaccharides in the arterial wall and, in particular, the role of these compounds in the mechanism of lipid deposition. He had found that lipid could be adsorbed to mucopolysaccharide and could thereby be deposited in the arterial wall. He regarded this as one of the main mechanisms which led to the development of the atheromatous plaque.

Mr. W. J. S. Still (London) described electron microscopic studies in experimental atherosclerosis. Electron microscopic studies of dietary-induced aortic athero. sclerosis in the rat and the rabbit show that lipid-bearing cells are capable of penetrating the intact endothelium. In contrast, when individual endothelial cells degenerate, lipid-bearing cells from the intima appear to extrude into the lumen. Ultra-microseopy also shows that two main cell types are present in all intimal lesions : first. foam cells, with complex lipid inclusions, and secondly, smaller cells with simple lipid inclusions. 'These coll types appear to be largely derived from the blood and aortic smooth muscle respectively.

R. N. FrenNeis

\title{
THE EXPANDING EARTH?
}

\author{
By PROF. L. EGYED \\ Geophysical Institute, Eötvös University, Budapest
}

$\mathrm{T}$ HE change of the Earth's dimensions is an old problem occurring mainly in connexion with mountain building and the moving or origin of continents. Generally, the first problem suggests contraction, while the second expansion of the Earth.

The comments made by J. G. Dennis ${ }^{1}$ referring to a communication by C. H. Barnet $t^{2}$ necessitate the summarizing of the idea of expansion. According to our knowledge Mantovani ${ }^{3}$ was the first, at the end of the nineteenth century, to apply the idea of expansion to the explanation of the similarity of the Atlantic coast lines.
B. Lindemann ${ }^{4}$ was the next, who derived the expansion of the Earth from an excess of heat generated by radio. active elements existing in the Earth's interior. As it has been shown lately ${ }^{5,6}$, heat is responsible for a very limited expansion only. The same idea was supported by Bogolepov ${ }^{7}$, showing its probability on different geological features.

O. C. Hilgenberg ${ }^{8}$ in 1933 was the first to construct a contiguous sialic surface on a sphere of a diameter about half of that of the present Farth and consisting of the present continents connected by shelves. But he had to 